\title{
Regulation of DR-5 protein and mitochondrial transmembrane potential by gemcitabine, a possible mechanism of gemcitabine-enhanced TRAIL-induced apoptosis
}

\author{
JAE-WON SEOL ${ }^{1}$, ATUL A. CHAUDHARI ${ }^{1}$, YOU-JIN LEE ${ }^{1}$, HYUNG-SUB KANG $^{1}$, IN-SHIK KIM ${ }^{1}$, \\ NAM-SOO KIM ${ }^{1}$, JIN-HO PARK ${ }^{1}$, TAE-HYUNG KIM ${ }^{2}$, DAI-WU SEOL ${ }^{3}$ and SANG-YOUEL PARK ${ }^{1}$ \\ ${ }^{1}$ Center for Healthcare Technology Development, College of Veterinary Medicine, Chonbuk National University, Jeonju, \\ Jeonbuk 561-756, South Korea; ${ }^{2}$ Department of Biochemistry, Chosun University School of Medicine, Dong-Gu, \\ Gwangju 501-759, Korea; ${ }^{3}$ Department of Surgery, University of Pittsburgh School of Medicine, Pittsburgh, PA 15261, USA
}

Received March 22, 2007; Accepted May 29, 2007

\begin{abstract}
Tumor necrosis factor (TNF)-related apoptosisinducing ligand (TRAIL) is a member of the TNF family and a potent inducer of apoptosis. Gemcitabine, chemotherapeutic agent is well known to be involved in synergistic cytotoxic effect with TRAIL. But the mechanism of this synergistic effect is still unclear. To examine the effects and synergistic mechanism of gemcitabine on TRAIL-induced apoptosis, A549, HCT116 and SNU638 cells were pretreated with gemcitabine and treated with TRAIL protein. Gemcitabine significantly enhanced A549 cell death induced by TRAIL, but it was inhibited by the pan-caspase inhibitor, Z-VADfmk. The combined treatment of both induced the activation of caspase- 8 and reduced the mitochondrial transmembrane potential (MTP) and also translocated Bax protein and released the cytochrome-C in A549 cells when compared with that of negative control. In addition, the gemcitabine pretreatment up-regulated DR-5 and p53 protein expression in a time-dependent manner, which suggests the possible involvement of the p53 protein as a transcriptional factor for DR-5 up-regulation. Thus, we report our findings that gemcitabine enhanced the TRAIL-induced apoptosis and the apoptotic signals are mediated by DR-5-dependent pathway and mitochondrial pathway. Taken together, gemcitabine enhanced TRAIL-induced apoptosis via DR-5 up-regulation and lowering MTP, and suggest that gemcitabine may be used as a successful chemotherapeutic agent for ligand type tumor therapy combined with TRAIL.
\end{abstract}

\section{Introduction}

Unlike necrosis, apoptosis is a fundamental biochemical process involving the selective and controlled elimination of

Correspondence to: Dr Sang-Youel Park, College of Veterinary Medicine, Chonbuk National University, Jeonju, Jeonbuk 561-756, South Korea

E-mail: sypark@chonbuk.ac.kr

Key words: gemcitabine, TRAIL, apoptosis, DR-5, mitochondrial transmembrane potential cells in multicellular organisms during normal cellular differentiation and development (1-4). It is characterized by membrane blebbing, nuclear fragmentation, formation of apoptosomes and also involved in tissue homeostasis, aging, various pathological processes and irreversible cell injury $(5,6)$. There is increasing evidence suggesting that apoptosis may be directly involved in many human degenerative diseases, autoimmune disorders and neoplasia (7-9). A misregulation or failure of apoptosis can result in the development of cancer and the resistance to antitumor treatment might be due to insensitivity to the induction of apoptosis. Therefore, apoptosis is a mechanism that needs to be exploited when developing new chemotherapies for cancer so that the new targets upon which to base chemotherapies will become apparent.

Gemcitabine [2',2'-difluorodeoxycytidine $(\mathrm{dFdC})]$ is a novel deoxycytidine analogue with activity against leukemia and a variety of solid tumors including non-small cell lung cancer (10). This drug is phosphorylated intracellularly to produce active triphosphate and diphosphate nucleotide forms. The difluorodeoxycytidine triphosphate competitively inhibits DNA polymerase and terminates DNA-chain elongation. The diphosphate form reduces the deoxynucleotide pools by inhibiting the activity of ribonucleotide reductase that allows a more rapid phosphorylation of gemcitabine, which enables to decrease its metabolic clearance by deoxycytidine monophosphate deaminase. In vitro, gemcitabine inhibits the proliferation and induces the apoptosis of HL60, myeloma, plasma cell leukemia and human T lymphoblastoid CEM cell lines (11). Previous evidence suggests that gemcitabine can induce apoptosis by engaging various pathways including the mitochondrial pathway, caspase activation, p53-dependent pathway, down-regulation of p8 mRNA expression $(12,13)$. Gemcitabine is an attractive drug to combine with a wide range of anticancer drugs on account of its synergistic effects. In synergy with hyperthermia, gemcitabine was reported to enhance apoptosis in human non-small cell lung cancer cells through caspase- 3 activation in vitro (14). Moreover, this drug is also a potent radiosensitizer of human tumor cells. There are few reports of this effect in solid tumor cell lines (15). 
TRAIL is a recently identified member of the TNF family that also activates the cognate receptor molecules through trimerization in a similar manner to other TNF family members $(3,16)$. DR-4/TRAIL-R1 and DR-5/TRAIL-R2 are intact TRAIL-Rs through which various apoptotic signals are transmitted into the cytoplasm. In contrast, DcR 1 and DcR2 are truncated TRAIL-Rs with a deletion of the cytoplasmic regions containing the death domains. Therefore, the overexpression of DcR1 and DcR2 blocks the functions of DR-4 and DR-5 in TRAIL-induced apoptosis, probably by competing with DR-4 or DR-5 for TRAIL. Although TRAIL is a member of the TNF family, there are some notable differences from TNF- $\alpha$ and FasL. Unlike Fas, whose expression is limited to certain tissues, TRAIL-Rs are expressed widely. This means that most tissues and cell types may be TRAIL targets. TRAIL has a unique selectivity for triggering apoptosis in tumor cells and might be less active against normal cells. Recent preclinical studies have demonstrated that the repeated systemic administration of the recombinant TRAIL protein effectively limited tumor growth without any serious side effects $(17,18)$. As a result, TRAIL has attracted considerable attention as a promising treatment for human cancer.

Several studies have indicated gemcitabine as a promising drug for the treatment of lung cancer (19). In addition, a combination of TRAIL gene therapy and chemotherapy has proved to be effective against various metastatic diseases (20). Therefore, this study investigated the apoptotic effect of gemcitabine in the small cell lung cancer line, A549. Furthermore, the effect of gemcitabine on TRAIL-induced apoptosis was investigated. The results showed that pretreatment with gemcitabine enhanced TRAIL-induced apoptosis accompanied by reduced mitochondrial tramsmembrane potential and DR-5 up-regulation. Our results thus suggest that the pretreatment of gemcitabine with TRAIL bypass the TRAIL-resistant defects in A549 cell line by up-regulating DR-5 expression and the combination can be used as a successful chemotherapeutic treatment.

\section{Materials and methods}

Cell culture. HCT116 (colon cancer), SNU638 (gastric cancer) and A549 (lung carcinoma) cells were obtained from the ATCC (The Global Bioresource Center) and were maintained in the suggested culture medium supplemented with $10 \%(\mathrm{v} / \mathrm{v})$ fetal bovine serum and antibiotics $(100 \mu \mathrm{g} / \mathrm{ml}$ gentamycin and $100 \mu \mathrm{g} / \mathrm{ml}$ penicillin-streptomycin). The cell cultures were incubated in an atmosphere containing $5 \% \mathrm{CO}_{2}$ at $37^{\circ} \mathrm{C}$.

Cell viability test. A549 cells were plated at $1.0 \times 10^{4}$ cells in a 12 -well plate, and incubated at $37^{\circ} \mathrm{C}$ for $24 \mathrm{~h}$. The cells were treated with different doses $(0,25,50,100$ and $200 \mu \mathrm{M})$ of gemcitabine (Lilly France S.A.) for different times (0, 3, 6, 12 and $24 \mathrm{~h})$. After a pretreatment with gemcitabine $(100 \mu \mathrm{M})$ for $24 \mathrm{~h}$, the recombinant TRAIL (100 $\mathrm{ng}$ ) protein was added to the culture media and coincubated for $3 \mathrm{~h}$. The cell morphology was photographed under an optical microscope, and the cell viability was determined using the crystal violet staining method as described elsewhere (21). Briefly, the cells were stained with a staining solution $(0.5 \%$ crystal violet in $30 \%$ ethanol and $3 \%$ formaldehyde) for $10 \mathrm{~min}$ at room temperature, washed 4 times with water, and dried. The cells were then lysed with a $1 \%$ SDS solution, and measured at $550 \mathrm{~nm}$. The cell viability was calculated from the relative dye intensity and compared with the controls.

DNA fragmentation test. The cells were harvested and washed with phosphate-buffered saline. The pellet was lysed in $0.5 \mathrm{ml}$ of a DNA lysis buffer (10 mM Tris, $1 \mathrm{mM}$ EDTA, $0.2 \%$ Triton X-100). Proteinase K $(0.5 \mathrm{mg} / \mathrm{ml})$ (Sigma-Aldrich, Steinheim, Germany) was then added to the tubes. The lysates were incubated for $1 \mathrm{~h}$ at $50^{\circ} \mathrm{C}$. After incubation, the samples were extracted once with phenol. The DNA was precipitated with 2 volumes of ethanol in the presence of $3 \mathrm{M}$ sodium acetate and washed with $70 \%$ ethanol. The pellet was dried in a vacuum drier and dissolved in a TE buffer (10 mM Tris, $1 \mathrm{mM}$ EDTA, $\mathrm{pH}$ 7.4). The RNA was removed by an RNase $\left(20 \mu \mathrm{g} / \mathrm{ml}\right.$ ) treatment at $37^{\circ} \mathrm{C}$ for $1 \mathrm{~h}$. A loading buffer (Sigma) was added to the tubes, and $3 \mu \mathrm{g}$ of DNA was loaded on $1.2 \%(\mathrm{w} / \mathrm{v})$ agarose for $2 \mathrm{~h}$ at $75 \mathrm{~V}$. The DNA laddering was visualized under UV light by staining the agarose gel with ethidium bromide.

Evaluation of mitochondrial transmembrane potential (MTP). The level of mitochondrial energization was determined using a lipophilic cation, 5,5',6,6'-tetrachlo-1,1'3,3'-tetraethylbenzimidazol-carbocyanine iodide (JC-1, Molecular Probes Eugene, OR, USA). This method is based on the ability of the fluorescent probe to enter the mitochondria selectively and reversibly change its color from green to orange as the MTP increases. JC- 1 exists as a monomer at low MTP values and shows a green fluorescence, while it forms an aggregate at a high MTP and shows a red fluorescence. This fluorescence can be measured at $530 \mathrm{~nm}$ (emission of JC-1 monomeric form) and $590 \mathrm{~nm}$ (emission of JC-1 aggregate) when excited at $490 \mathrm{~nm}$. Briefly, after the gemcitabine $(100 \mu \mathrm{M})$ treatment with and without TRAIL $(100 \mathrm{ng} / \mathrm{ml})$ for the indicated time, the cells were collected by centrifugation, washed twice with a PBS buffer and resuspended in $500 \mu \mathrm{l}$ PBS containing JC-1 at a concentration of $10 \mu \mathrm{M}$. After $30 \mathrm{~min}$ incubation at $37^{\circ} \mathrm{C}$, the cells were photographed using a fluoroscope. The fluorescence was monitored with a fluorescence plate reader (SpectraMax fluorometer with SoftMax Programme, Molecular Probes, USA), which allows for sequential measurement of each well at the wavelengths mentioned above. The values were compared with those of the negative control.

Western blot assay. The whole cell lysates were prepared by harvesting the cells, washing them in cold phosphate-buffered saline, resuspending them in a lysis buffer $25 \mathrm{mM}$ HEPES (pH 7.4), $100 \mathrm{mM}$ EDTA, $5 \mathrm{mM} \mathrm{MgCl}_{2}, 0.1 \mathrm{mM}$ DTT, and protease inhibitor mixture] and sonicating the lysate. The proteins $(40 \mu \mathrm{g})$ were separated on a $12-15 \%$ SDS gel and transferred to a nitrocellulose membrane. After incubation for $1 \mathrm{~h}$ with a 1:1000 primary antibody dilution buffer $(1 \%$ milk with PBS-Tween), the membranes were developed by enhanced chemiluminescence using a secondary antibody dilution. Caspase-8, cytochrome c, DR-5 and Bax were probed with the antibody obtained from BD Pharmingen (San Diego, CA), and p53 antibodies were obtained from Santa Cruz (Santa Cruz, CA). 
A

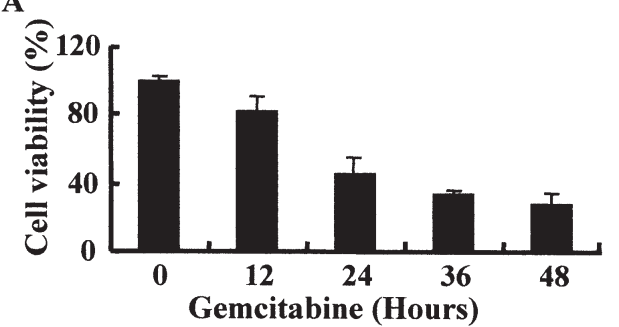

B

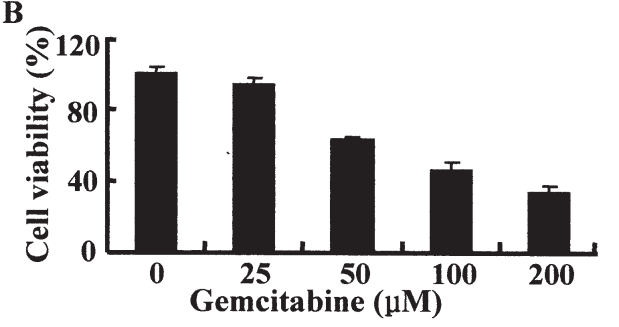

Figure 1. Gemcitabine induces apoptotic cell death in a time/dose-dependent manner. (A) A549 cells plated in 12-well were treated with gemcitabine $(100 \mu \mathrm{M})$ for the indicated time. Cell viability was determined by crystal violet staining method. Viability of control cells was set at $100 \%$, and viability relative to the control was presented. The experiments were performed in triplicated at least twice. (B) A549 cells plated in 12-well were treated with gemcitabine $(24 \mathrm{~h})$ for the indicated dose. Cell viability was determined as described in (A).

Cellular fractionation. A549 cells were resuspended in mitochondrial buffer $(210 \mathrm{mM}$ sucrose, $70 \mathrm{mM}$ mannitol, $1 \mathrm{mM}$ EDTA, $10 \mathrm{mM}$ HEPES), broken by 6 passages through a 25 -gauge needle and subjected to centrifugation at $700 \mathrm{~g}$ to pellet nuclei. The post-nuclear supernatant was centrifuged at $10000 \mathrm{~g}$ for $30 \mathrm{~min}$ to pellet the mitochondrial enriched heavy membrane fraction and the supernatant was used as cytosolic fraction. Total proteins were subjected to Western blot analysis.

\section{Results}

Induction of apoptotic cell death and DNA fragmentation in A549 cells by gemcitabine. Gemcitabine has been shown to induce apoptosis in myeloma, HL60, and pancreatic cancer cells (11). To explore this effect in A549 lung adenocarcinoma cells we treated the cells with gemcitabine for the indicated doses and times. As shown in Fig. 1, gemcitabine induced apoptosis in a time- and dose-dependent manner. For different time periods, a 24-h treatment with gemcitabine led to almost $50 \%$ apoptosis and the percentage of cells undergoing apoptosis increased to $70-80 \%$ after 36 and $48 \mathrm{~h}$ of exposure, respectively. However, $70 \%$ of the cells were found to be viable after 12-h exposure (Fig. 1A). In addition, the gemcitabine treatment at various doses for $24 \mathrm{~h}$ showed a direct relationship between the dose and percentage of apoptotic cells. A549 cells were found to be more sensitive at high doses such as 100 and $200 \mu \mathrm{M}$ (Fig. 1B). The photomicrographs also revealed that the cells had apoptotic morphology when exposed to high doses (Fig. 2A). Gemcitabine also induced DNA fragmentation into nucleosomal size at high doses (100 and $200 \mu \mathrm{M})$ thus corresponding with the cell viability results (Fig. 2B). Overall, these results showed that, at high dose and long-term exposure gemcitabine depressed cell viability in A549 cells and the apoptotic cell death was accompanied by DNA damage.

A

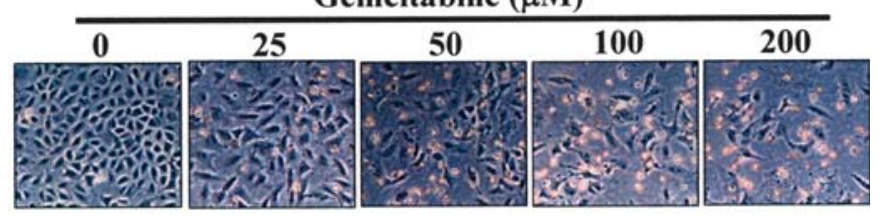

B

Gemcitabine $(\mu \mathrm{M})$

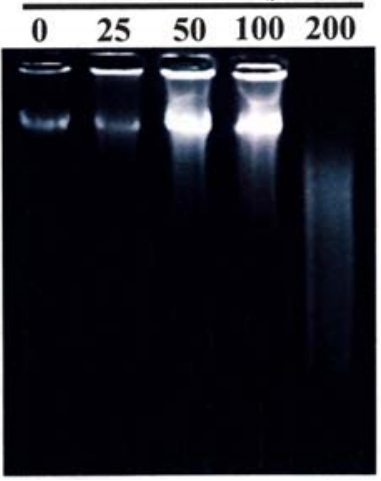

Figure 2. Gemcitabine induces apoptotic cell death and DNA degradation in a dose-dependent manner. (A) A549 cells plated in 12-well were treated with gemcitabine $(24 \mathrm{~h})$ for the indicated dose. Cell morphology was photographed by microscope (x200). (B) A549 cells in tissue culture dish (100x20 mm) were treated with gemcitabine $(24 \mathrm{~h})$ for the indicated dose. DNA $(3 \mu \mathrm{g})$ was loaded on $1.2 \%$ agarose for $2 \mathrm{~h}$ at $75 \mathrm{~V}$. DNA laddering was visualized under UV light by staining the agarose gel with ethidium bromide.

Sensitization of cells to TRAIL-induced apoptosis by gemcitabine. Various studies have shown that gemcitabine enhanced TRAIL-induced apoptosis in a variety of cells such as pancreatic cancer cells, mesothelioma cell lines and prostate cancer cell lines $(22,23)$. Under a wide range of TRAIL protein concentrations, even up to $200 \mathrm{ng} / \mathrm{ml}$, the A549 cells were found to be significantly resistant to TRAILinduced apoptosis when exposed for $3 \mathrm{~h}$ (data not shown). Therefore, the effect of gemcitabine on TRAIL resistant A549 cell line was investigated by exposing A549 cells to gemcitabine $(100 \mu \mathrm{M})$ for $24 \mathrm{~h}$, followed by a 3-h treatment with the recombinant human TRAIL protein $(100 \mathrm{ng} / \mathrm{ml})$. TRAIL alone induced $20 \%$ cell death after the $3 \mathrm{~h}$ but pretreatment with gemcitabine enhanced TRAIL induced cell death by $>66 \%$ (Fig. 3A). Gemcitabine pretreatment was also observed for TRAIL-induced apoptosis in other cell lines such as HCT 116 (human colon cancer cell) and SNU 638 (gastric cancer cell). But, pancaspase inhibitor, Z-VAD-fmk, slightly inhibited cell death by the treatment of gemcitabine with TRAIL in all cell lines. The cell morphology also supports this enhanced effect by clearly showing an increased number of apoptotic cells in the case of gemcitabine and TRAIL (Fig. 3B).

Effect of pretreatment of gemcitabine with TRAIL on mitochondrial transmembrane potential. The mechanism involved in enhanced apoptoic effect by the combined treatment of both drugs was examined by measuring the MTP potential using the $\mathrm{JC}-1$ probe, as described in Materials and methods. Photomicrographs and the fluorescence values indicate that gemcitabine and TRAIL together led to loss in MTP though the gemcitabine alone treatment induced only 

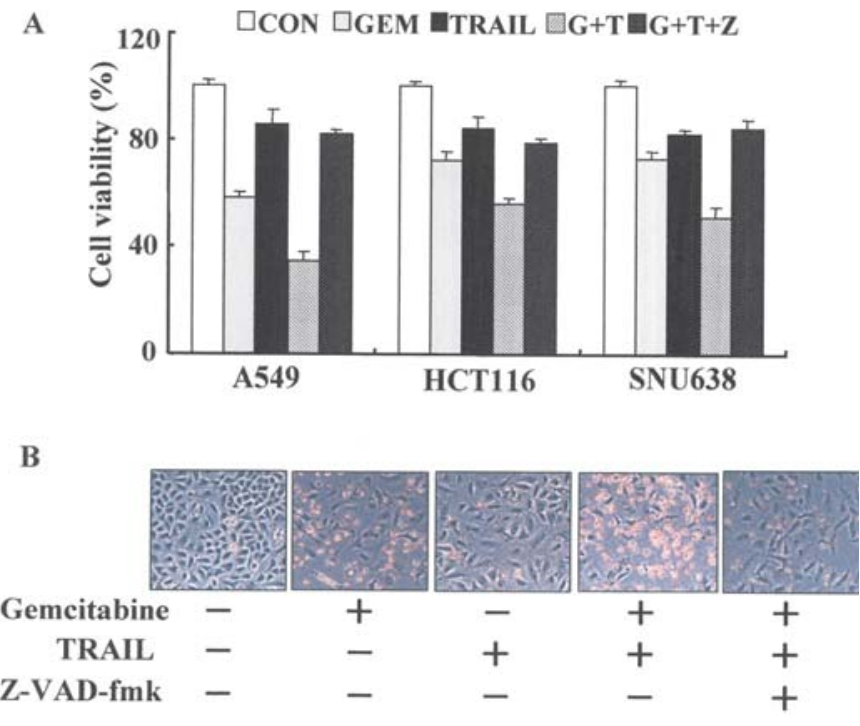

Figure 3. Effect of gemcitabine on TRAIL-induced apoptosis. (A) A549, HCT116 and SNU638 cells plated in 12-well were pretreated with gemcitabine $(100 \mu \mathrm{M})$ and Z-VAD-fmk $(100 \mu \mathrm{M})$ for $24 \mathrm{~h}$, and then coincubated with or without recombinant TRAIL protein $(100 \mathrm{ng} / \mathrm{ml})$ for additional $3 \mathrm{~h}$. Cell viability was determined by crystal violet staining method. Viability of control cells was set at $100 \%$, and viability relative to the control is presented. The experiments were performed at triplicate, at least twice. (B) Cell morphology under the conditions as described in (A) was photographed at $\mathrm{x} 200$.

\section{A}

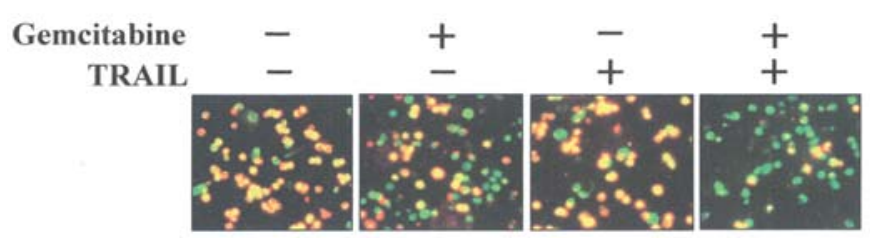

B

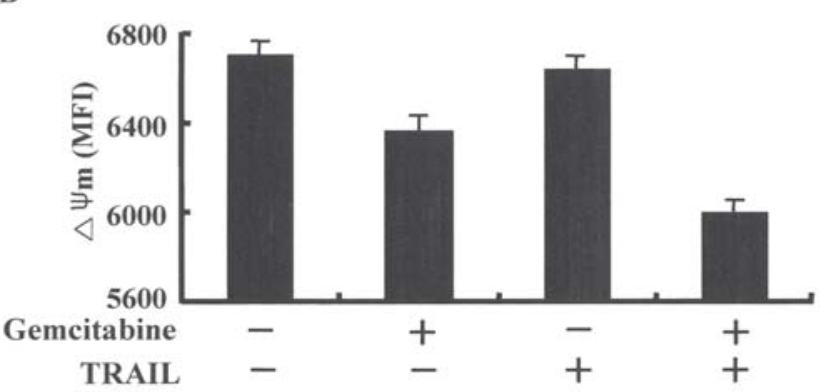

Figure 4. The change of mitochondrial transmembrane potential (MTP) on pre-treatment of gemcitabine with TRAIL. (A) A549 cells plated in 6-well were pretreated with gemcitabine $(100 \mu \mathrm{M})$ for $24 \mathrm{~h}$, and then coincubated with or without recombinant TRAIL protein $(100 \mathrm{ng} / \mathrm{ml})$ for additional $3 \mathrm{~h}$. MTP was determined using JC-1 probe. The cells were photographed using a fluoroscope. (B) The red fluorescence intensity was measured under the conditions as described in (A) at $530 \mathrm{~nm}$ (emission of JC-1 monomeric form) when excited at $490 \mathrm{~nm}$. The mean fluorescence intensity values are indicated.

slight loss in MTP. As previously described in Materials and methods, at high mitochondrial transmembrane potential, the JC-1 dye forms an aggregate and shows a red fluorescence but at a low MTP it shows a green fluorescence because of

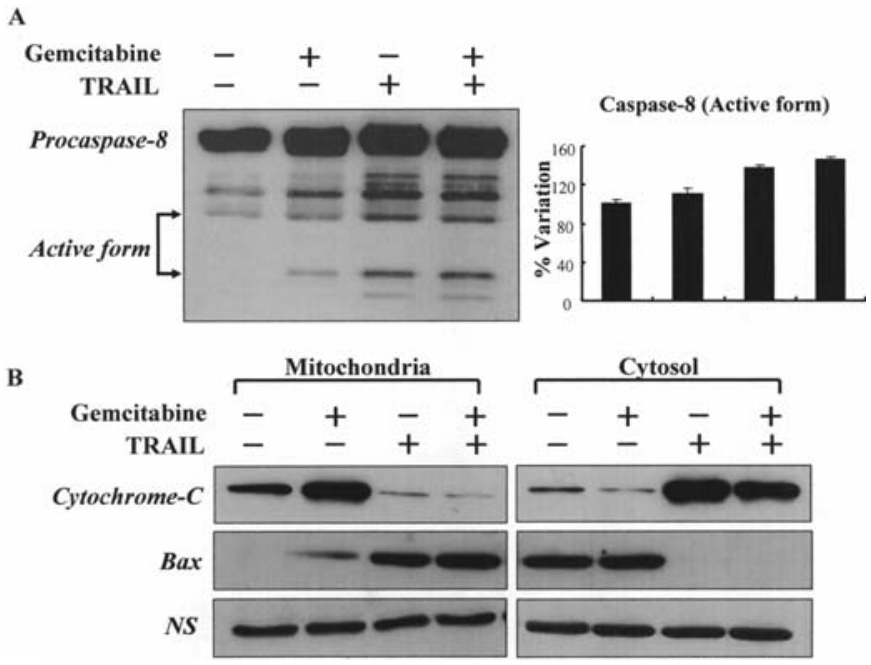

Figure 5. Western blot analysis in A549 cells exposed to gemcitabine and recombinant TRAIL protein. (A) A549 cells were pretreated with gemcitabine $(100 \mu \mathrm{M})$ for $24 \mathrm{~h}$, and then coincubated with or without recombinant TRAIL protein $(100 \mathrm{ng} / \mathrm{ml})$ for an additional $1 \mathrm{~h}$. Whole cell lysates were prepared and protein sample (40 $\mu \mathrm{g})$ was separated on SDS gel, analyzed for caspase8 protein by Western blot analysis. The blots were quantified by laser scanning desitometry. (B) A549 cells were treated under the conditions as described in (A). Cell lysates for mitochondria and cytosol were prepared, protein sample (20 and $40 \mu \mathrm{g}$ ) was separated on SDS gel, analyzed for Bax protein and cytochrome c by Western blot analysis. NS indicates a nonspecific protein band that was used to ensure equal protein loading.
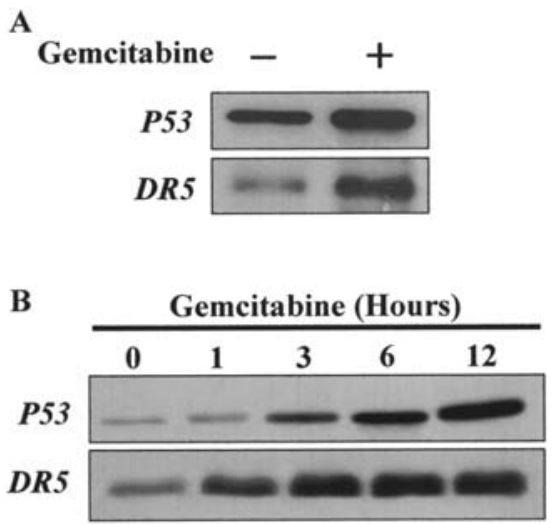

Figure 6. Western blot analysis of DR-5 and p53 in A549 cells exposed to gemcitabine and TRAIL protein, and gemcitabine treatment in timedependent manner. (A) A549 cells were treated with gemcitabine $(100 \mu \mathrm{M})$ for $24 \mathrm{~h}$. Whole cell lysates were prepared and the protein sample $(40 \mu \mathrm{g})$ was separated on SDS gel, analyzed for DR-5 and p53 protein by Western blot analysis. (B) A549 cells treated with gemcitabine $(100 \mu \mathrm{M})$ for the indicated time.

the inability of JC-1 to form an aggregate. The fluoroscopic results presented in Fig. 4A show the cells with green fluorescence after the gemcitabine and TRAIL treatment indicating lower MTP values. In contrast, the negative control cells showed red fluorescence, which indicates high MTP values. However, cells treated only with TRAIL or gemcitabine showed slight green fluorescence indicating a very small change in MTP values by a single treatment with these drugs. Moreover, the fluorescence values clearly showed high red fluorescence for the control compared with that of the combined gemcitabine and TRAIL treatment 
(Fig. 4B). However, the red florescence values for the single treatments showed slight variations as compared with the control. Overall, a gemcitabine pretreatment followed by TRAIL reduces the mitochondrial transmembrane potential in A549 cells.

Enhancement of apoptotic protein expression after combined treatment of TRAIL and gemcitabine. In order to gain some insight into the apoptotic proteins involved, the expression of caspase- 8 and cytochrome $\mathrm{c}$ and Bax were investigated by Western blot analysis. The gemcitabine pretreatment followed by TRAIL increased the activation of the caspase- 8 proteins compared with that of the TRAIL and gemcitabine treatments alone (Fig. 5A). Using densitometry, we established densitometeric values for each band. The result showed that the combined gemcitabine and TRAIL treatment significantly increased the expression of apoptotic protein as compared with the control. In addition, cytosolic and mitochondrial fractions were examined for Bax and cytochrome $\mathrm{c}$ protein expression. As shown in Fig. 5B, the combined treatment of gemcitabine and TRAIL translocated Bax protein from cytosol to mitochondria and both treatments also released cytochrome c protein from mitochondria to cytosol. This results suggests that a gemcitabine pretreatment followed by TRAIL reduced the MTP and increased the expression of Bax and the release of cytochrome $\mathrm{c}$ from the mitochondria. Taken together, our results indicate that the enhanced effect of the combined treatment occurs via extrinsic and intrinsic pathways.

Up-regulation of DR-5 expression by gemcitabine. Previous studies have shown that TRAIL in concert with other chemotherapeutic agent such as doxorubicin induced apoptosis in mesothelioma cell lines independent of DR-5 up-regulation (22). In the same study, the effect of gemcitabine and TRAIL together was also studied which showed enhanced apoptosis in M28 and REN cell lines. But for these cell lines, there was no data of DR-5 expression by gemcitabine. The clinical studies for cytotoxic effects of gemcitabine and cisplatin suggested DR-5 and Bcl-2 status as useful factors for predicting the efficacy of gemcitabine and cisplatin chemotherapy (24). Therefore, in order to check the effect of gemcitabine on DR5 protein expression, A549 cells were exposed to gemcitabine $(100 \mu \mathrm{M})$ for $12 \mathrm{~h}$ and analyzed by Western blotting. Gemcitabine was able to up-regulate DR5 protein expression, which suggest that up-regulation of DR-5 expression by gemcitabine enhanced TRAIL-induced apoptosis in A549 cells and it may be related to p53 expression (Fig. 6A). Also, Liu et al suggested that DR-4 was up-regulated by p53 protein expression (25). Therefore, to evaluate whether p53 can up-regulate DR-5 protein, we performed Western blot analysis after exposing the cells to gemcitabine for various time periods (Fig. 6B). After a 3-h treatment, gemcitabine enhanced p53 expression and further increased after 6 and $12 \mathrm{~h}$. Interestingly, there was a simultaneous increase of DR-5 and p53 protein expression with increasing gemcitabine-exposure time, which indicates that DR-5 protein expressions may be regulated by p53 protein as a transcriptional factor.

\section{Discussion}

Several pathways have been suggested for the induction of apoptosis by gemcitabine in many cell lines. Some include caspase activation, either p53-dependent or p53-independent, a mitochondrial pathway, and via CD95 expression $(12,13,26,27)$. It was shown that gemcitabine down-regulates p8 mRNA expression in pancreatic cancer cells (28). In addition, the combination treatment of gemcitabine with other chemotherapeutic agents, such as staurosporin, paclitaxel and cisplatin, induced atypical apoptosis in BG-1 human ovarian cancer cells (10). Also, gemcitabine-induced apoptosis is mediated by the MKK3/6-p38 MAPK-caspase signaling pathway in pancreatic cancer cells (29). Chang et al reported that ERK (extracellular signal-regulated kinase) activation and Akt inactivation mediated the gemcitabineinduced apoptosis in human NSCLC H1299 cells, independently of p53 (26). The present study showed the involvement of p53 in gemcitabine-induced apoptosis of A549 cells.

Gemcitabine is a promising compound for the treatment of human lung cancer. Bandala et al suggested the role of IAP proteins in gemcitabine induced apoptosis in non-small cell lung cancer cells (15). Gemcitabine induced apoptosis in multiple myeloma cell lines, and its activity required caspase activation (25). Although apoptosis has been shown to play a role in certain cell types with gemcitabine, the steps leading to cell death after the drug-target interaction are not well known. This study showed that gemcitabine induced apoptotic cell death in both a time- and dose-dependent manner, and increased the expression levels of the proapoptotic proteins such as caspase-3, active caspase- 8, p21 and p53 (data not shown). These results are similar to those showing that gemcitabine induces cell death via caspase activation in BxPC-3 human pancreatic adenocarcinoma and MM1.S human myeloma cells $(11,30)$. In addition, the increase in p21 and p53 protein expression showed that gemcitabine can induce cell death via a caspase-independent pathway in A549 cells. Extracellular signal-regulated kinase (ERK) activation and Akt inactivation were reported to mediate gemcitabine-induced apoptosis independently of p53 in human NSCLC H1299 cells (11). In pancreatic cancer cells, it was reported that p53 restoration enhanced gemcitabine-induced apoptosis (12). Our study showed that a gemcitabine treatment causes DNA damage and ultimately the expression of the p53 protein in A549 cells. Therefore, we suggest the p53-dependent pathway as a caspaseindependent pathway for induction of apoptosis by gemcitabine in A549 cells.

Several studies have shown that a combined treatment with gemcitabine and various chemotherapeutic agents is a useful tool against tumor cells. Gefitinib in synergy with gemcitabine enhanced apoptosis in head and neck carcinoma cells by arresting the cell cycle and suppressing EGFR stimulation (31). A combined treatment with gemcitabine and topotecan caused cell cycle disturbances and induced apoptosis in human lung cancer cells (32). For these lung cancer cells, the combined treatment induced p53 and p21 expression. Similarly, we have also found that a gemcitabine treatment of the A549 cells induced p53 and p21 expression in a dose-dependent manner (data not shown). Many studies 
have suggested that the synergy with gemcitabine is useful for enhancing the therapeutic effect. It was recently reported that hyperthermia and gemcitabine enhance apoptosis in human non-small cell lung cancer cells by increasing the caspase- 3 activity (14). Therefore, we investigated the synergistic effect of gemcitabine on TRAIL-induced apoptosis in A549 cells. A gemcitabine pretreatment followed by a TRAIL treatment induced caspase- 8 activation in the A549 cell line indicating increased caspase activity as a possible pathway for the enhanced effect of gemcitabine in TRAIL resistant A549 cells.

TRAIL is a TNF family member with DR-4 and DR-5 as its receptors, which are widely expressed in most tissues and cell types. Furthermore, TRAIL induces apoptosis in a wide variety of tumor cells but not in most normal cells. Previous studies have shown that apoptotic cell death can be induced in pancreatic cancer cells by a TRAIL treatment and is mediated through the activation of caspase- 3 and -8 . In addition, the combined treatment of gemcitabine and TRAIL significantly increased the antitumor effect of TRAIL (23). TRAIL and chemotherapy (doxorubicin, cis-platinum, etoposide and gemcitabine) can act cooperatively to kill mesothelioma cells, not by increasing the expression of the DR-5 receptor, but in association with mitochondrial amplification of apoptotic signals (22). Also, Sheikh et al reported that all the four TRAIL receptors are regulated by p53 (33), for DR-5 it was first shown that its transcription is directly transactivated by p53 through an intronic sequence-specific p53BS $(34,35)$. In addition, Liu et al reported that p53 directly regulates the expression of the DR-4 gene via the novel intronic p53 binding site (25). Our results suggest that a gemcitabine pretreatment can enhance TRAIL-induced apoptosis, compared with TRAIL alone, by up-regulating DR-5 and significantly increasing the expression of the apoptotic proteins such as caspase- 8 and Bax. Moreover, the both treatment reduced the mitochondrial trans-membrane potential in A549 cells, thereby causing release of cytochrome c from mitochondria.

Thus, we suggest that a pretreatment of gemcitabine enhances TRAIL-induced apoptosis via a caspase-dependent and mitochondrial pathway. Moreover, we have shown that gemcitabine has the potential to enhance TRAIL-induced apoptosis in A549 cells, which are resistant to TRAILinduced apoptosis by up-regulation of DR-5 expression by gemcitabine. The data for a simultaneous increase in the DR-5 protein level with p53 expression suggest that p53 might be involved in the up-regulation of DR- 5 by gemcitabine as was suggested previously for TRAIL receptors expression regulated by $\mathrm{p} 53$.

In conclusion, gemcitabine induced apoptosis in both, time- and dose-dependent manner, and enhanced TRAILinduced apoptosis in A549 cells by up-regulating DR-5 expression and lowering MTP. Thus, the combined treatment of gemcitabine with TRAIL might be useful in cancer therapy, particularly in TRAIL-resistant cancer cells.

\section{Acknowledgements}

This study was supported by the Regional Research Centers Program of the Korean Ministry of Education and Human Resources Development through the Center for Healthcare
Technology Development, 2nd stage Brain Korea 21 project and partially supported by international collaborative research funds of Chonbuk National University (ICR-2006-003), 2006.

\section{References}

1. Ellis RE, Yuan JY and Horvitz HR: Mechanisms and functions of cell death. Annu Rev Cell Biol 7: 663-698, 1991.

2. Raff MC: Social controls on cell survival and cell death. Nature 356: 397-400, 1992

3. Wiley SR, Schooley K, Smolak PJ, et al: Identification and characterization of a new member of the TNF family that induces apoptosis. Immunity 3: 673-682, 1995.

4. Wyllie AH, Kerr JF and Currie AR: Cell death: the significance of apoptosis. Int Rev Cytol 68: 251-306, 1980.

5. Jacobson MD, Weil M and Raff MC: Programmed cell death in animal development. Cell 88: 347-354, 1997.

6. Raff MC: Size control: the regulation of cell numbers in animal development. Cell 86: 173-175, 1996.

7. Green DR, Bissonnette RP and Cotter TG: Apoptosis and cancer. Important Adv Oncol pp 37-52, 1994.

8. Carson DA and Ribeiro JM: Apoptosis and disease. Lancet 341 : 1251-1254, 1993.

9. Carson DA and Tan EM: Apoptosis in rheumatic disease. Bull Rheum Dis 44: 1-3, 1995 .

10. Cartee L, Kucera GL and Willingham MC: Induction of apoptosis by gemcitabine in BG-1 human ovarian cancer cells compared with induction by staurosporine, paclitaxel and cisplatin. Apoptosis 3: 439-449, 1998.

11. Chandler NM, Canete JJ and Callery MP: Caspase-3 drives apoptosis in pancreatic cancer cells after treatment with gemcitabine. J Gastrointest Surg 8: 1072-1078, 2004.

12. Cascallo M, Calbo J, Capella G, Fillat C, Pastor-Anglada M and Mazo A: Enhancement of gemcitabine-induced apoptosis by restoration of p53 function in human pancreatic tumors. Oncology 68: 179-189, 2005.

13. Ferreira CG, Span SW, Peters GJ, Kruyt FA and Giaccone G: Chemotherapy triggers apoptosis in a caspase-8-dependent and mitochondria-controlled manner in the non-small cell lung cancer cell line NCI-H460. Cancer Res 60: 7133-7141, 2000.

14. Vertrees RA, Das GC, Popov VL, Coscio AM, Goodwin TJ, Logrono R, Zwischenberger JB and Boor PJ: Synergistic interaction of hyperthermia and gemcitabine in lung cancer. Cancer Biol Ther 4: 1144-1153, 2005.

15. Bandala E, Espinosa M, Maldonado V and Melendez-Zajgla J: Inhibitor of apoptosis-1 (IAP-1) expression and apoptosis in nonsmall-cell lung cancer cells exposed to gemcitabine. Biochem Pharmacol 62: 13-19, 2001.

16. Pitti RM, Marsters SA, Ruppert S, Donahue CJ, Moore A and Ashkenazi A: Induction of apoptosis by Apo-2 ligand, a new member of the tumor necrosis factor cytokine family. J Biol Chem 271: 12687-12690, 1996.

17. Walczak H, Miller RE, Ariail K, Gliniak B, Griffith TS, Kubin M, Chin W, Jones J, Woodward A, Le T, Smith C, Smolak P, Goodwin RG, Rauch CT, Schuh JC and Lynch DH: Tumoricidal activity of tumor necrosis factor-related apoptosisinducing ligand in vivo. Nat Med 5: 157-163, 1999.

18. Griffith TS, Anderson RD, Davidson BL, Williams RD and Ratliff TL: Adenoviral-mediated transfer of the TNF-related apoptosis-inducing ligand/Apo-2 ligand gene induces tumor cell apoptosis. J Immunol 165: 2886-2894, 2000.

19. Bunn PA Jr and Kelly K: New chemotherapeutic agents prolong survival and improve quality of life in non-small cell lung cancer: a review of the literature and future directions. Clin Cancer Res 4: 1087-1100, 1998.

20. Lin T, Zhang L, Davis J, Gu J, Nishizaki M, Ji L, Roth JA, Xiong $M$ and Fang B: Combination of TRAIL gene therapy and chemotherapy enhances antitumor and antimetastasis effects in chemosensitive and chemoresistant breast cancers. Mol Ther 8: 441-448, 2003.

21. Park SY, Billiar TR and Seol DW: Hypoxia inhibition of apoptosis induced by tumor necrosis factor-related apoptosisinducing ligand (TRAIL). Biochem Biophys Res Commun 291: 150-153, 2002.

22. Liu W, Bodle E, Chen JY, Gao M, Rosen GD and Broaddus VC: Tumor necrosis factor-related apoptosis-inducing ligand and chemotherapy cooperate to induce apoptosis in mesothelioma cell lines. Am J Respir Cell Mol Biol 25: 111-118, 2001. 
23. Xu ZW, Kleeff J, Friess H, Buchler MW and Solioz M: Synergistic cytotoxic effect of TRAIL and gemcitabine in pancreatic cancer cells. Anticancer Res 23A: 251-258, 2003.

24. Han JY, Hong EK, Choi BG, Park JN, Kim KW, Kang JH, Jin JY, Park SY, Hong YS and Lee KS: Death receptor 5 and Bcl-2 protein expression as predictors of tumor response to gemcitabine and cisplatin in patients with advanced non-small-cell lung cancer. Med Oncol 20: 355-362, 2003.

25. Liu X, Yue P, Khuri FR and Sun SY: p53 up-regulates death receptor 4 expression through an intronic p53 binding site. Cancer Res 64: 5078-5083, 2004.

26. Chang GC, Hsu SL, Tsai JR, Wu WJ, Chen CY and Sheu GT: Extracellular signal-regulated kinase activation and Bcl-2 downregulation mediate apoptosis after gemcitabine treatment partly via a p53-independent pathway. Eur J Pharmacol 502: 169-183, 2004.

27. Christgen M, Schniewind B, Jueschke A, Ungefroren H and Kalthoff H: Gemcitabine-mediated apoptosis is associated with increased CD95 surface expression but is not inhibited by DN-FADD in Colo357 pancreatic cancer cells. Cancer Lett 227: 193-200, 2005.

28. Giroux V, Malicet C, Barthet M, Gironella M, Archange C, Dagorn JC, Vasseur S and Iovanna JL: p8 is a new target of gemcitabine in pancreatic cancer cells. Clin Cancer Res 12: 235-241, 2006.
29. Habiro A, Tanno S, Koizumi K, Izawa T, Nakano Y, Osanai M, Mizukami Y, Okumura T and Kohgo Y: Involvement of p38 mitogen-activated protein kinase in gemcitabine-induced apoptosis in human pancreatic cancer cells. Biochem Biophys Res Commun 316: 71-77, 2004.

30. Nabhan C, Gajria D, Krett NL, Gandhi V, Ghias K and Rosen ST: Caspase activation is required for gemcitabine activity in multiple myeloma cell lines. Mol Cancer Ther 1: 1221-1227, 2002.

31. Chun PY, Feng FY, Scheurer AM, Davis MA, Lawrence TS and Nyati MK: Synergistic effects of gemcitabine and gefitinib in the treatment of head and neck carcinoma. Cancer Res 66: 981-988, 2006.

32. Giovannetti E, Mey V, Danesi R, Basolo F, Barachini S, Deri M and Del Tacca M: Interaction between gemcitabine and topotecan in human non-small-cell lung cancer cells: effects on cell survival, cell cycle and pharmacogenetic profile. Br J Cancer 92: 681-689, 2005.

33. Sheikh MS and Fornace AJ Jr: Death and decoy receptors and p53-mediated apoptosis. Leukemia 14: 1509-1513, 2000.

34. Takimoto R and El-Deiry WS: Wild-type p53 transactivates the KILLER/DR5 gene through an intronic sequence-specific DNAbinding site. Oncogene 19: 1735-1743, 2000.

35. Wu GS, Burns TF, McDonald ER III, Jiang W, Meng R, Krantz ID, Kao G, Gan DD, Zhou JY, Muschel R, Hamilton SR, Spinner NB, Markowitz S, Wu G and El-Deiry WS: KILLER/DR5 is a DNA damage-inducible p53-regulated death receptor gene. Nat Genet 17: 141-143, 1997. 